\title{
Effect of an Interventional Program on Pregnant Women's Knowledge and Attitude Toward Mode of Delivery at Beni - Suef City, Egypt
}

\author{
Safaa Soliman Ahmed Mohamed ${ }^{1, *}$, Hanan Fawzy Elsayed Ali ${ }^{2}$, Abeer Mohammed Elmaghawry ${ }^{3}$, \\ Eman Hessien Heggy ${ }^{4}$
}

${ }^{1}$ Maternal and Newborn Health Nursing, Nursing Faculty, Beni-Sueif University, Beni-Suef City, Egypt

${ }^{2}$ Maternal and Newborn Health Nursing, Nursing Faculty, Helwan University, Helwan City, Egypt

${ }^{3}$ Community and Family Health Nursing, Nursing Faculty, Beni-Suef University, Beni-Suef City, Egypt

${ }^{4}$ Medical Surgical Nursing, Nursing Faculty, Mansoura University, Mansoura City, Egypt

Email address:

madoalshamy@live.com (S. S. A. Mohamed)

${ }^{*}$ Corresponding author

\section{To cite this article:}

Safaa Soliman Ahmed Mohamed, Hanan Fawzy Elsayed Ali, Abeer Mohammed Elmaghawry, Eman Hessien Heggy. Effect of an Interventional Program on Pregnant Women's Knowledge and Attitude Toward Mode of Delivery at Beni -Suef City, Egypt. American Journal of Nursing Science. Vol. 6, No. 2, 2017, pp. 135-140. doi: 10.11648/j.ajns.20170602.18

Received: January 3, 2017; Accepted: January 13, 2017; Published: February 27, 2017

\begin{abstract}
Background: The rate of caesarean section (CS) has been increasing among women in Egypt, However, it is selected by pregnant women without medical rationales and justification, thus the wrong concepts and knowledge can play a role on decision for selecting CS as the easier mode of delivery. Aim: To evaluate the effect of an interventional program on pregnant women's knowledge and attitude toward mode of delivery at Beni -Suef city. Methods: A quasi-experimental research design was used in this study composed of 287 primiparous women with normal pregnancy at 34-36 weeks of gestational age and with no indication to cesarean section was selected from antenatal clinic at Beni Suef general Hospital. The study was conducted from April to September 2016. Data collection tools: a structured interview questionnaires part I, Sociodemographic characteristics, part II; Knowledge Test regarding mode of delivery, and part III, Attitude Test regarding normal and cesarean delivery. Results: the study findings was reported that significantly higher total scores of pregnant women's knowledge $(\mathrm{P}=0.00)$ toward caesarian section after intervention compared with before intervention program. As regard to attitude of women toward cesarean section significantly decreased scores indicating lower positive attitude to cesarean section after intervention $(\mathrm{P}=0.00)$. Conclusion: based on the study findings and Hypothesis there were improvement of pregnant women's knowledge toward the mode of delivery. Recommendations: Based on the results study recommended that urgent preventive measures should be taken to reduce the high rate of cesarean deliveries by improving women's knowledge toward the advantage and disadvantage for different modes of delivery which can lead to positive attitude.
\end{abstract}

Keywords: Knowledge, Attitude, Vaginal Delivery, Caesarian Section, Educational Program

\section{Introduction}

Nowadays, when the access to obstetric care is upgrading day by day has been concern over the increasing cesarean section (CS) delivery mode rates over the world. Modes of delivery divided to vaginal delivery (VD) and CS; unfortunately, cesarean section is one of the most frequently performed options among women $[1,2]$. Furthermore, the modern delivery option among obstetrics is the CS, it is consider easier mode of delivery, hence CS rate is a major public health problem for mothers and babies as well as increase the cost outcome compared with normal option of deliveries [3].

The indications for performing CS are gestational diabetes, pre-eclampsia, failure to progress in labor, failed induction and dystocia [4-7]. On the other hand the some benefit reported in the literature as malpresentation, cord prolapse, 
fetal distress and large size baby, moreover some benefits for both other and fetus such as abnormal placenta, cephalopelvic disproportion [8].

Evidence reports that pregnant women who is knowledgeable about her condition can be able to deiced, which option is appropriate in relation to her and fetus conditions [9]. According to world health organization (WHO) has reported about ten to fifteen percent of all prenatal women develops serious complications and need skilled management including CS [10]. On other hand, Sanavi et al, was reported that women's beliefs and perception regarding C.S play an important significant role in the decision making to select the mode of deliveries not depend on the pregnancy condition but sometimes depend on the cultural values, social support, women's knowledge and attitude [11].

Moreover, recent study done at Iran reported that the effects of husbands' education of pregnant women on knowledge, attitude, and reducing elective cesarean section and found the implementation of educational program on husbands can be effective and increase the wives' knowledge and attitude to reduce the cesarean section rate [12]. So, the present study was conducted with the aim to assess and compare the effectiveness of educational program on the women's knowledge and attitude toward C.S.

\section{Significant of the Study}

The rate of caesarean section (CS) has been increasing among women in Egypt, However, it is selected by pregnant women without medical rationales and justification, thus the wrong concepts and knowledge can play a role on decision for selecting CS as the easier mode of delivery.

\section{Aim of the Study}

To evaluate the Effect of An interventional program on pregnant women's knowledge and attitude toward mode of delivery at Beni -Suef city

\section{Research Questions}

(a) Are pregnant women having poor knowledge regarding mode of delivery?

(b) Are pregnant women having negative attitude regarding mode of delivery?

(c) Is an interventional program enhancing women's knowledge and attitude regarding mode of delivery?

\section{Hypothesis}

(a) Study samples have poor knowledge regarding mode of delivery before implementing the program.

(b) Study samples have negative attitude regarding mode of delivery before implementing the program..

(c) The interventional program will be enhancing women's knowledge and attitude regarding mode of delivery.

\section{Subjects and Methods}

\subsection{Study Design}

A quasi-experimental research design was used in this the study.

\subsection{Technical Design}

Technical designs for this study were included research setting, subjects, tools and methods of data collection as the following:-

\subsubsection{Setting}

The study was implemented at antenatal clinic general hospital

\subsubsection{Sample}

Non probability purposive sample composed of 287 primiparous women with normal pregnancy at 34-36 weeks of gestational age and with no indication to cesarean section were selected from antenatal clinic at Beni Suef general Hospital. The sample size was calculated according to the ratio of cesarean section monthly at year 2015, among the women which ranging from 65-70 SC peer month.

\subsubsection{Exclusion Criteria}

Women with any medical problems (Hypertension, Diabetes, Anemia,....... ect), multipara and with no indication of cesarean section.

\subsection{Tool of Data Collection}

Data was collected using structure interview questioner tool developed by researcher based on literature review. It contains four main parts:

\subsubsection{Socio-Demographic Data}

Was includes questions regarding a socio-demographic characteristics of the study sample and family such as age, income, educational level, .........etc) and obstetrical history.

\subsubsection{Knowledge Test Regarding Mode of Delivery}

It was developed by researcher based on literature review which included questions related normal delivery and cesarean section such definition, advantage, disadvantage, indication, hazard of normal and SC delivery.

\subsubsection{Attitude Test Regarding Normal and Cesarean Delivery}

Attitude scale was developed by researcher based on literature review which included 10 items to assess women regarding normal and cesarean delivery.

\subsection{Ethical Consideration}

Written consent was obtained from hospital directors, head of the department of Obstetrics \& Gynecology and head nurses of antenatal clinic at general hospital after explaining the aim of the study to them in order to obtain permission and help.

A brief explanation of the purpose and importance of the 
study was given to the women and assured that the obtained information will be confidential and used only the purpose of the study. Confidentiality of the information was assured by the researcher and clarifies to the participated women their right to withdraw from the study any time.

\subsection{Operational Design}

The operational design includes preparatory phase, content validity, reliability, pilot study and fieldwork.

\subsubsection{Preparatory Phase}

It includes reviewing of literature, different studies and theoretical knowledge of various aspects of the problems using books, articles, internet, periodicals and magazines.

\subsubsection{Validity \& Reliability of Tool}

Tool was developed based on the identified needs and demands of the study sample. Also, it was done by expertise from obstetric medical and nursing field professor, Family and Community nursing professor in the field. Reliability: was measuring by follow up sheet through pilot study to measuring fixation degree.

\subsubsection{Pilot Study}

Pilot study was carried out after the development of the tools on $10 \%$ of women to test the applicability of the study tools and to estimate any need for addition in the tool. Then necessary modifications were done according to the results of pilot study and expertise opinions. Otherwise, women included in the pilot study were then excluded from the study sample to avoid bias in the data.

\subsection{Field Work}

\subsubsection{Assessment Phase}

In this stage, the researcher assessed women knowledge and attitude using tool of data collection. The tool was filled in about 10 minutes to and 30 minutes.

\subsubsection{Educational Guidelines Development Phase}

The guidelines were developed based on the identified needs and demands of women gathered in phase I, in the light of the most recent pertinent literature. This phase included the following; theoretical session were carried out with discussion (10 minutes) to assess women's level of knowledge and attitude regarding mode of delivery, then the researcher started the education time. Phase II: including two sessions, the first one was included guidelines regarding definition, advantage and disadvantage of normal and SC delivery. The second session was covered guidelines regarding indication, hazards of normal and SC delivery. Phase III: Finally evaluation phase: It takes two weeks to assess women's knowledge and attitude regarding mode of delivery with the same tool which was used at pretest phase. and labour sheet takes by telephone to confirm type of delivery, cause, place, and attendance person, gestational age at labour. The study was conducted from April to September 2016.

\subsubsection{Administrative Design}

Written letter including the aims of the study were issued from the Dean of Faculty of Nursing, to the director of antenatal clinic at general hospital. To seek their approval for carrying out the study.

\subsection{Statistical Design}

Data was collected and entered into a database file. Statistical analysis was performed by using the SPSS18 computer software statistical package. Data was described by summary tables and figures, Chi-2 or Fisher Exact test was used. Statistical significance was considered at $\mathrm{P}$-value $<0.05$ and highly Significance at P-value $<0.00$. Graphs were done for data visualization and using Microsoft Excel.

\section{Results}

Table 1: indicates socio-demographic characteristics of women in the study sample. Nearly half of study women had secondary education (48.4) and more than half from urban residence (51.9). In relation to job, around two third of study women were employed (61.7) and (71.1) of them had an income level enough for living.

Table 1. Indicates socio-demographic characteristics of women in the study sample $(N=287)$.

\begin{tabular}{lll}
\hline Item & No. & $\%$ \\
\hline Education: & & \\
primary & 29 & 10.1 \\
middle & 139 & 48.4 \\
university & 119 & 41.5 \\
Job: & & \\
house & 177 & 61.7 \\
wife-working & 110 & 38.3 \\
Residence: & & \\
rural & 138 & 48.1 \\
Urban & 149 & 51.9 \\
Income: & & \\
Insufficient & 47 & 16.4 \\
Sufficient & 204 & 71.1 \\
sufficient and saving & 36 & 12.5 \\
\hline
\end{tabular}

Table 2 shows, mode of delivery among women in study sample, more than one third of them (38.3) were delivered normally with episiotomy, while less than half of them (40.4) elective caesarean section. Also, (12.2) of the study sample have emergency caesarean section and most reasons (48.5), (20.0) was reported to premature rupture of membrane fatal distress respectively.

Table 2. Shows, mode of delivery among women in study sample $(N=287)$.

\begin{tabular}{lll}
\hline Items & No. & $\%$ \\
\hline Mode of delivery: & & \\
1-Vaginal birth (No. 136) & & \\
- Normal vaginal delivery without episiotomy: & 26 & 9.1 \\
- Normal vaginal delivery with episiotomy: & 110 & 38.3 \\
Caesarean section (No. 151) & & \\
- Emergency caesarean: & 35 & 12.2 \\
- Elective caesarean & 116 & 40.4 \\
Total & 287 & $100 \%$ \\
Reasons for emergency caesarean section & & \\
\hline
\end{tabular}




\begin{tabular}{lll}
\hline Items & No. & $\%$ \\
\hline a) Premature rupture of membrane & 17 & 48.5 \\
b) Placental abruption & 2 & 5.7 \\
c) Fatal distress & 7 & 20.0 \\
d) labour is very long (first stage) & 4 & 11.4 \\
e) Nuchal cord & 5 & 14.3 \\
\hline
\end{tabular}

Figure 1: show that distribution of the study sample according to person who responsible for delivery. It clarify that most of them (85.7) delivered by doctor and (14.3) of them by nurse.

Table 3: shows, distribution of study sample according to their knowledge regarding types of labor (CS\& Normal) before and after the program, as table shows there are highly significant differences in women knowledge before and after intervention.

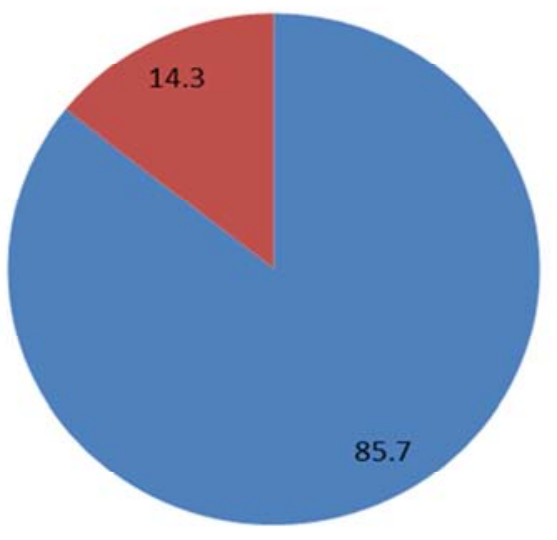

Doctor:

nurse:

Figure 1. Distribution of the study sample according to person who responsible for delivery.

Table 3. Distribution of study sample according to their knowledge regarding mode of delivery (CS. \& normal) before and after the program.

\begin{tabular}{|c|c|c|c|c|c|c|}
\hline \multirow{2}{*}{ Items } & \multicolumn{2}{|l|}{ Pre } & \multicolumn{2}{|l|}{ Post } & \multirow{2}{*}{$\mathbf{X}^{2}$} & \multirow{2}{*}{ p-value } \\
\hline & No. & $\%$ & No. & $\%$ & & \\
\hline \multicolumn{7}{|c|}{ Knowledge related to normal delivery: } \\
\hline Poor & 208 & 72.5 & 0 & 0.0 & \multirow{3}{*}{7.469} & \multirow{3}{*}{$0.006 * *$} \\
\hline Inadequate & 79 & 27.5 & 55 & 19.2 & & \\
\hline Adequate & 0 & 0.0 & 232 & 80.8 & & \\
\hline \multicolumn{7}{|c|}{ Knowledge related to caesarean section: } \\
\hline Poor & 200 & 69.7 & 10 & 3.5 & \multirow{3}{*}{21.646} & \multirow{3}{*}{$0.000 * *$} \\
\hline Inadequate & 68 & 23.7 & 72 & 25.1 & & \\
\hline Adequate & 19 & 6.6 & 205 & 71.4 & & \\
\hline
\end{tabular}

Knowledge about ND: Poor $=0-6$, inadequate $=7-12$, adequate $=13-18$

Knowledge about Cs.: poor $=0-7$, inadequate $=8-15$ adequate $=16-23$

Table 4: illustrates, distribution of study sample according to their attitude regarding types of labor (CS \& normal) before and after the program, as seen in the table there are highly significant differences in women positive attitude toward normal delivery after intervention. Additionally there are highly significant differences in women negative attitude toward cesarean section after intervention.

Table 4. Distribution of study sample according to their attitude regarding mode of delivery (C.S \& normal) before and after the program.

\begin{tabular}{|c|c|c|c|c|c|c|}
\hline \multirow{2}{*}{ Items } & \multicolumn{2}{|l|}{ Pre } & \multicolumn{2}{|c|}{ Post } & \multirow{2}{*}{$\mathrm{X}^{2}$} & \multirow{2}{*}{ p-value } \\
\hline & No. & $\%$ & No. & $\%$ & & \\
\hline \multicolumn{7}{|c|}{ Attitude related to normal delivery: } \\
\hline Positive & 22 & 7.7 & 251 & 87.4 & & \\
\hline Not sure & 32 & 11.2 & 26 & 9.1 & 77.743 & $0.000 * *$ \\
\hline Negative & 233 & 81.1 & 10 & 3.5 & & \\
\hline \multicolumn{7}{|c|}{ Attitude related to caesarean section: } \\
\hline Positive & 211 & 73.5 & 5 & 1.7 & & \\
\hline Not sure & 76 & 26.5 & 86 & 30 & 232.615 & $0.000 * *$ \\
\hline Negative & 0 & 0 & 196 & 68.3 & & \\
\hline
\end{tabular}

Attitude about type of delivery (Normal \& CS): Negative $=0-3$, Not sure $=4-6$, Positive $=7-10$ 
Table 5: reveals; the relation between women's knowledge and attitude before and after the program as table shows there is a highly significant positive correlation between women's knowledge and attitude after intervention.

Table 5. The Relation between mother's knowledge and attitude before and after the program.

\begin{tabular}{lll}
\hline Item: & Pearson correlation & P value \\
\hline $\begin{array}{l}\text { Relation between mother's } \\
\text { knowledge and attitude: }\end{array}$ & & \\
1. Before program: & 0.078 & 0.192 \\
2. After program & 0.396 & $0.000^{* *}$ \\
\hline
\end{tabular}

\section{Discussion}

The world health organization reported the acceptable percentage for CS is $10 \%$ to $15 \%$. Recently the rate has been increasing irregularly [13]. the present study was done on 287 primpara pregnant women at 34-36 weeks of gestational age, the result was referred that, more than one third of them (38.3) were delivered normally with episiotomy, while less than half of the study sample (40.4) elective caesarean section. Also,(12.2) of the study sample have emergency caesarean section and most reasons (48.5),(20.0) was reported to premature rupture of membrane fatal distress respectively.. However, these aforementioned present study findings are in disagreement with Ajeet et al; (2011) studied women's knowledge, perceptions, and potential demand towards caesarean section and potential demand towards caesarean section and found the majority of women selected vaginal delivery $(91.5 \%)$ [1].

In same line with the study finding, the study conducted in Iran and reported from 600 deliveries, only $99(16.5 \%)$ the delivery option were vaginal delivery and the majority about $501 \quad(83.5 \%)$ were CS deliveries. Depending on aforementioned results, they recommended to follow prompt multidisciplinary action to reduce the unacceptable rising rate of CS and improving women's knowledge about benefits of different mode of delivers and consequences that may lead towards vaginal delivery, however their recommendation in congruence with the present study [14].

Moreover, Tschudin et al; 2009 have described specific strategies used to increase pregnant women's awareness of and attitudes towards cesarean section demand, as well as to focus in their perception of CS which based on misconceptions [15]. One of the of the Egyptian researches done at Gamal Abed Elnaser hospital, Alexandria from 1998 to 2005 reported that CS was very high and trend to increase and was significant, unfortunately this will be as an indicator to take appropriate strategies to reduce the rate of $\mathrm{CS}$, patient's records lack for essential information that can give justification for CS [16]. Women who were insist to deliver by vagina mode of delivery generally felt that CS is very dangerous, and painful, while the women who were selected an optional CS had less pain [17].

The pre-post program improvement in women's knowledge and attitude toward cesarean section significantly decreased scores indicating lower positive attitude to cesarean section However, these aforementioned present study findings are in agreement with Naeimi et al (2015), they were focused on the low level of women's awareness and neutral attitude towards CS must be improved by counseling, conducting training programs for pregnant women and implement the normal vaginal delivery as a first option in the policy of the hospital if no condition in need to shift to CS [18].

Moreover, and in line with the present study findings, study conducted by Aziken et al in Nigeria and proved that the educational program can increase the women's understanding and perception of CS as a method of delivery in Nigeria [19]. The foregoing present study finding concerning on the educational program improves women's knowledge and attitude towards the CS.

\section{Conclusion}

Knowledge is considering the main factor that affecting health outcomes and the first line to adapting a healthy attitude, educational program, so based on the main study findings it is concluded that the predictor of women's knowledge improvement was the program attendance regarding to the risk and benefits of CS and hence the positive attitude towards vaginal delivery. As well as it is recommended that similar this educational program must be implemented on a wider scale and evaluate further improvement.

\section{Recommendation}

In the light of the study findings, the following is recommended:

- Husbands or spouse should be attending the sessions of educational program.

- A simple manual of guidelines of care for pregnant women should be made available in all antenatal units to be provided to newly pregnant women.

- Nurses need to be trained on administration of counseling to new pregnant women because she can change the women's knowledge and attitude.

- Further research is needed to assess the long-term effects of such program

\section{References}

[1] Ajeet S, Jaydeep N, Nandkishore K, Nisha R. Women's Knowledge, Perceptions, And Potential Demand Towards Caesarean Section. National Journal of Community Medicine, 2011; Vol 2 Issue 2.

[2] Gita, A. Caesarean section: Evaluation, guidelines and recommendations. Indian Journal of Medical Ethics. 2008; 5 (3).

[3] Naymi RS, Rehan N. Prevalence and determinants of caesarean section in a Teaching Hospital of Pakistan. J Obstet Gynaecol. 2000; 20: 479-83. 
[4] Langer A, Villar J. promoting evidence based practice in maternal care. BMJ. 2002; 324: 928-9.

[5] Wagner M. Choosing cesarean section. Lancet. 2000; 356 (11): 1677-80.

[6] Aisien A, Lawson J, Adebayo A. A five year appraisal of cesarean section in a Northen Nigeria University Teaching Hospital. Niger Postgrad Med J. 2002; 9 (3): 146-50.

[7] Asenova D, Stambolov B. Incidence and indications for cesarean section in the obstetrics clinic in the university hospital of obstetrics and gynecology "Maichin Dom" in Sofia. Akush Ginekol. 2005; 3: 15-7.

[8] Sims C, Meyn L, Caruana R, Rao R, Mitchell T, krohn M. Predicting cesarean delivery with decision tree models. Am J Obstet Gynaecol. 2000; 183 (5): 1-12.

[9] Sanavi, A. A. Moghaddam, M. F. Shovey, et al. Effective education to decrease elective caesarean section. J Pak Med Assoc; 2014 Vol. 64, 500-505.

[10] Sufang, G., Padmadas, S. S., Fengmin, Z., Brown, J. J., \& Stones, R. W. Delivery settings and caesarean section rates in China: Bulletin of the World Health Organization, 2007; 85, 755-762.

[11] Johanson R., Newburn M., Macfarlane A. Has the medicalization of childbirth gone too far?. BMJ. 2002; 24: 892-5.

[12] Sharifirad G, Rezaeian M, Soltani R, Javaheri S, Mazaheri MA. A survey on the effects of husbands' education of pregnant women on knowledge, attitude, and reducing elective cesarean section. J Educ Health Promot. 2013 Sep 30; 2: 50.
[13] Valiani M, Haghighatdana Z, Ehsanpour S. Comparison of childbirth training workshop effects on knowledge, attitude, and delivery method between mothers and couples groups referring to Isfahan health centers in Iran. Iran J Nurs Midwifery Res. 2014 Nov; 19 (6): 653-8.

[14] Ghotbi F, Akbari Sene A, Azargashb E, Shiva F, Mohtadi M, Zadehmodares S, Farzaneh F, Yasai FAWomen's knowledge and attitude towards mode of delivery and frequency of cesarean section on mother's request in six public and private hospitals in Tehran, Iran, J Obstet Gynaecol Res. 2014 May; 40 (5): 1257-66.

[15] Tschudin S, Alder J, Hendriksen S, Bitzer J, Popp KA, Zanetti R, Hösli I, Holzgreve W, Geissbühler V. Pregnant women's perception of cesarean section on demand. J Perinat Med. 2009; 37 (3): 251-6.

[16] Labib NY, Mortada MM, Guirguis WW, Abd El-Aziz HM. Cesarean section deliveries in one health insurance hospital in Alexandria. J Egypt Public Health Assoc. 2007; 82 (3-4): 299317.

[17] Adageba RK, Danso KA, Adusu A \& Ankobea F. Awareness and Perceptions of and Attitudes towards Caesarean Delivery among Antenatal. Ghana Med J. 2008; 42 (4): 137-140.

[18] Naeimi N, GHolami M, Qasemi A. A study of awareness and attitudes of pregnant women admitted to social security hospital in zahedan toward cesarean section. International Journal of Analytical, Pharmaceutical and Biomedical Sciences. 2015, Volume: 4: Issue-4.

[19] Aziken M, Omo-Aghoja L, Okonofua F. Perceptions and attitudes of pregnant women towards caesarean section in urban Nigeria. Acta Obstet Gynecol Scand. 2007; 86 (1): 42-7. 